\title{
PEMBUATAN BETON POROUS DENGAN MATERIAL GEOPOLIMER
}

\section{USE OF GEOPOLYMER IN POROUS CONCRETE}

\author{
Rofikatul Karimah ${ }^{1}$, Akbar Prasojo ${ }^{2}$ \\ 1,2Jurusan Teknik Sipil-Fakultas Teknik-Universitas Muhammadiyah Malang \\ Jl. Raya Tlogomas No. 246, Malang \\ email: rofikatulkarimah@gmail.com
}

\begin{abstract}
The increase of land that was impenetrable by water, which associated by increased settlements building, could causes the time for water infiltration become much shorter. The excess water will form suface runoff, as the surrounding land cannot absorb it all, even flood might happen when a heavy rainfall occurs. Therefore, it is important to build a sustainable drainage for settlements and porous concrete could be the choice. Porous concrete can be applicable for non-structural construction: parking area, sidewalk, pavement, and so on. Recent development that offer a great result is by inconporate fly ash as partial replacement for Portland cement using inorganic polimerization (geopolymer). This porous concrete with geopolymer material can be used as permeable structure and is expected to become alternative concrete material for non-structural element. This experimental study focuses on finding the optimum mix design that incorporating geopolymer material for concrete cylinder with $7,5 \mathrm{~cm}$ in diameter and $15 \mathrm{~cm}$ in height. The cement has been replaced by geopolymer material accordingly in the range of $10 \%, 15 \%, 20 \%$, $25 \%$ and $30 \%$. The experimental result shows that the optimum geopolymer replacement was $29 \%$, specimen with this concrete mix has compressive strength and porosity of $11 \mathrm{~N} / \mathrm{m} 2$ and $14 \%$ respectively. However, future study using admixture is needed to achieve desired compressive strength, permeability and workability of the porous concrete with geopolymer materials.
\end{abstract}

Keywords: Porous; Non-structural Concrete; Fly Ash.

\begin{abstract}
Abstrak
Meningkatnya luas daerah yang tertutup oleh perkerasan akibat pembangunan permukiman, seperti di daerah perkotaan, dapat mengakibatkan waktu berkumpulnya air menjadi jauh lebih pendek. Berkurangnya kesempatan air hujan berinfiltrasi ke dalam tanah akan menyebabkan terbentuknya limpasan permukaan atau bahkan banjir. Dalam upaya mengantisipasi hal tersebut, maka diperlukan penerapan mengenai drainase permukiman yang berwawasan lingkungan, seperti pembuatan perkerasan beton porous, sebatas untuk konstruksi non-struktural seperti parkir kendaraan, trotoar, lapangan, dan lain sebagainya. Perkembangan muktahir yang menjanjikan saat ini adalah penggunaan abu terbang sebagai pengganti sebagian semen Portland lewat proses yang disebut polimerisasi anorganik (geopolimer). Diharapkan dari pembuatan beton porous dengan material geopolimer ini, selain dapat menyerap air dengan cepat, juga dapat digunakan sebagai beton non-struktural. Metode penelitian ini bersifat eksperimen dengan mencari mix design geopolimer yang paling tepat dari benda uji silinder diameter ukuran 7,5 cm dan tinggi $15 \mathrm{~cm}$. Penelitian menggunakan campuran bahan pengganti semen Portland menggunakan material geopolimer pada benda uji silinder dan dibuat variasi prosentase $10 \%$, $15 \%, 20 \%, 25 \%$ dan $30 \%$. Berdasarkan hasil uji diperoleh variasi campuran geopolimer optimum pada $29 \%$ dengan kuat tekan beton $11 \mathrm{~N} / \mathrm{mm} 2$ dan porositas beton $14 \%$. Perlu ditemukan bahan tambah (Admixture) untuk mendapatkan kuat tekan, daya serap air, dan workability yang diinginkan pada pembuatan beton porous dengan material geopolimer.
\end{abstract}

Kata kunci: Beton Porous; Non Struktural; Abu Terbang.

\section{PENDAHULUAN}

Pengembangan permukiman di perkotaan mengakibatkan makin berkurangnya daerah resapan air hujan karena meningkatnya luas daerah yang ditutupi oleh perkerasan dan mengakibatkan waktu berkumpulnya air jauh lebih pendek, sehingga akumulasi air hujan yang terkumpul 
melampaui kapasitas drainase yang ada. Hal ini sering ditunjukan dengan terjadinya air yang meluap dari saluran drainase baik di perkotaan, maupun di permukiman secara khusus. Upaya mengurangi limpasan permukaan air hujan dan menambah infiltrasi ke dalam tanah adalah pembuatan beton lulus air (porous concrete).

Berbagai penelitian dan percobaan di bidang beton porous dilakukan sebagai upaya mengurangi limpasan permukaan air hujan dan menambah infiltrasi ke dalam tanah. Beton lulus air (porous concrete) adalah suatu elemen bahan bangunan yang dibuat dari campuran agregat kasar, semen hidrolis atau sejenisnya, air dan sedikit agregat halus membiarkan air hujan untuk menembus mendasari lahan. Tujuan dari beton lulus air (porous concrete) untuk mengalirkan air hujan dipermukaan ke lapisan dibawahnya melalui celah-celah beton, mengurangi kecepatan erosi tanah, khususnya pada tanah yang miring dan menghambat penguapan air tanah dibawahnya, sehingga dapat menjaga kelembaban dan keseimbangan air tanah.

Pemanfaatan material geopolimer yang digunakan sebagai beton porous dalam penelitian ini untuk menghasilkan beton yang ramah lingkugan karena pada proses pembuatan beton geopolimer tidak terlalu memerlukan energi, seperti halnya proses pembuatan klinker semen portland yang memerlukan suhu hingga 1450 derajat Celsius. Pemanasan lebih kurang 60 derajat Celsius selama satu hari penuh sudah dapat dihasilkan beton geopolimer. Oleh karena itu, pembuatan beton geopolimer mampu menurunkan emisi gas rumah kaca yang diakibatkan oleh proses produksi semen hingga tersisa $20 \%$.

Penelitian ini dilakukan untuk mencari nilai kuat tekan beton dan porousitas beton yang menggunakan material geopolimer.

Beton geopolimer terdiri atas agregat, waterglass, air, fly ash, gypsum, dan $\mathrm{NaOH}$. Bahan dasar pengikat yang digunakan dalam pembuatan beton lulus air adalah abu terbang (fly ash). Abu terbang tidak memiliki kemampuan mengikat seperti halnya semen portland. Tetapi dengan adanya air dan ukuran partikel yang halus, oksida silika yang dikandung oleh abu terbang akan bereaksi secara kimia dengan kalsium hidroksida yang terbentuk dari proses hidrasi semen dan menghasilkan zat yang memiliki kemampuan mengikat. Karenanya, penambahan atau penggantian dengan abu terbang dibandingkan semen portland memiliki keunggulan lebih kuat, lebih tahan cuaca, lebih ringan, harganya relatif murah, dan berpotensi menambah keawetan beton tersebut.

Menurut Agusandra (2013) Hasil dari kuat tekan beton geopolymer dengan fly ash sebagai bahan pengganti semen, didapatkan nilai kuat tekan beton tertinggi beton geopolymer $141.037 \mathrm{~kg} / \mathrm{cm}^{2}$, pada perbandingan rasio aktivator $\mathrm{Na}_{2} \mathrm{SiO}_{3}: \mathrm{NaOH}$ $=5: 2$.

Sanggapramana (2011) dalam penelitian pembuatan beton geopolymer dengan fly ash sebagai bahan pengganti semen, diperoleh grafik hubungan antara kuat tekan beton geopolymer terhadap perbandingan aktivator. Untuk beton geopolymer $70: 30$, kuat tekan tertinggi dimiliki oleh beton dengan perbandingan $\mathrm{Na} 2 \mathrm{SiO} 3: \mathrm{NaOH}=5: 2$ sebesar $141,037 \mathrm{~kg} / \mathrm{cm}^{2}$.

Geopolimer merupakan material ramah lingkungan yang biasa dikembangkan sebagai alternatif pengganti beton semen di masa mendatang. Bahan dasar utama pembuatan beton geopolimer adalah bahan yang banyak mengandung silicon dan alumunium. Unsurunsur ini, diantaranya banyak terdapat pada material buangan hasil sampingan industri, seperti abu terbang (fly ash) sisa pembakaran batu bara. Material geopolimer ini jika digabungkan dengan agregat batuan batuan akan menghasilkan beton geopolimer tanpa perlu semen lagi. Sintesa geopolimer aluminosilikat membutuhkan dua konstituen utama dalam reaksi pencampuran, yaitu: (1) Prekursor yang kaya akan kandungan Al dan Si bentuknya dapat berupa tanah liat, slag, silica fume, fly ash dan (2) larutan alkali silikat activator yang digunakan bisa berupa larutan $\mathrm{NaOH}$ atau larutan $\mathrm{KOH}$ dan larutan sodium silikat atau potassium silikat.

\section{METODE PENELITIAN}

\section{Lokasi Penelitian}

Pelaksanaan penelitian ini dilakukan di Laboratorium Beton Teknik Sipil Universitas Muhammadiah Malang yang dimulai dari pemeriksaan material, pembuatan benda uji, perawatan benda uji, dan pengujian benda uji. 


\section{Rancangan Penelitian}

Penelitian menggunakan campuran bahan pengganti semen menggunakan material geopolymer pada benda uji silinder ukuran diameter 7,5 cm dan tinggi $15 \mathrm{~cm}$ dan dibuat variasi prosentase sebanyak $10 \%, 15 \%$, $20 \%, 25 \%$ dan $30 \%$. Jumlah benda uji yang di digunakan dalam penelitian ini adalah 30 buah. di bagi menjadi 15 buah benda uji digunakan uji kuat tekan dan 15 benda uji digunakan untuk uji porousitas. Dengan jumlah yang sama dibuatlah benda uji beton dengan material semen sebagai perbandingan.

Tabel 1. Properti Benda Uji beton polymer

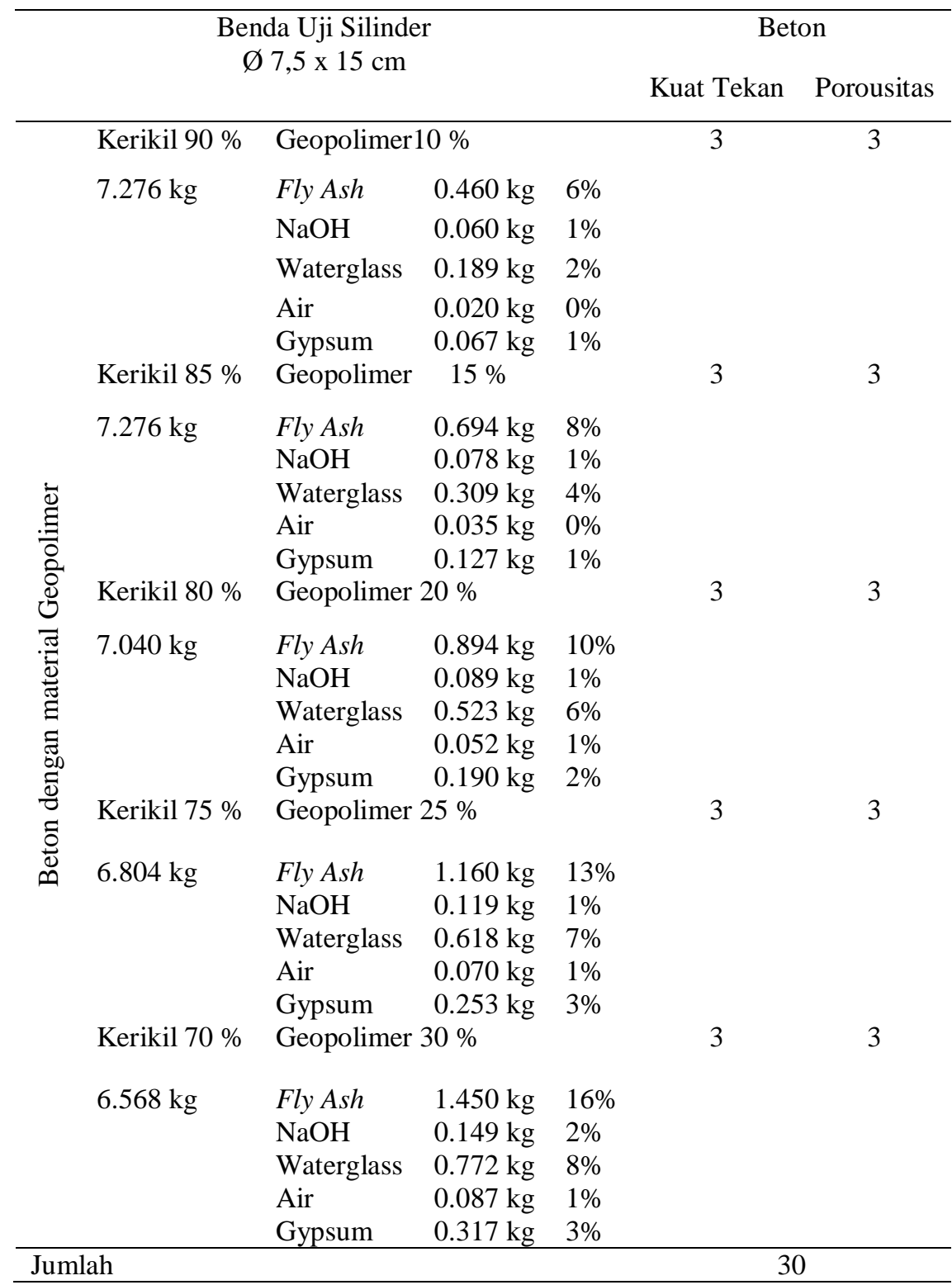

\section{HASIL DAN PEMBAHASAN}

\section{Kuat Tekan Beton}

Ada beberapa variasi campuran yang digunakan dalam penelitian ini. Setiap variasi menghasilkan kuat tekan beton yang berbeda. Hasil Pengujian kuat tekan beton tersaji pada Tabel 2. 
Tabel 2. Hasil Pengujian Kuat Tekan Beton

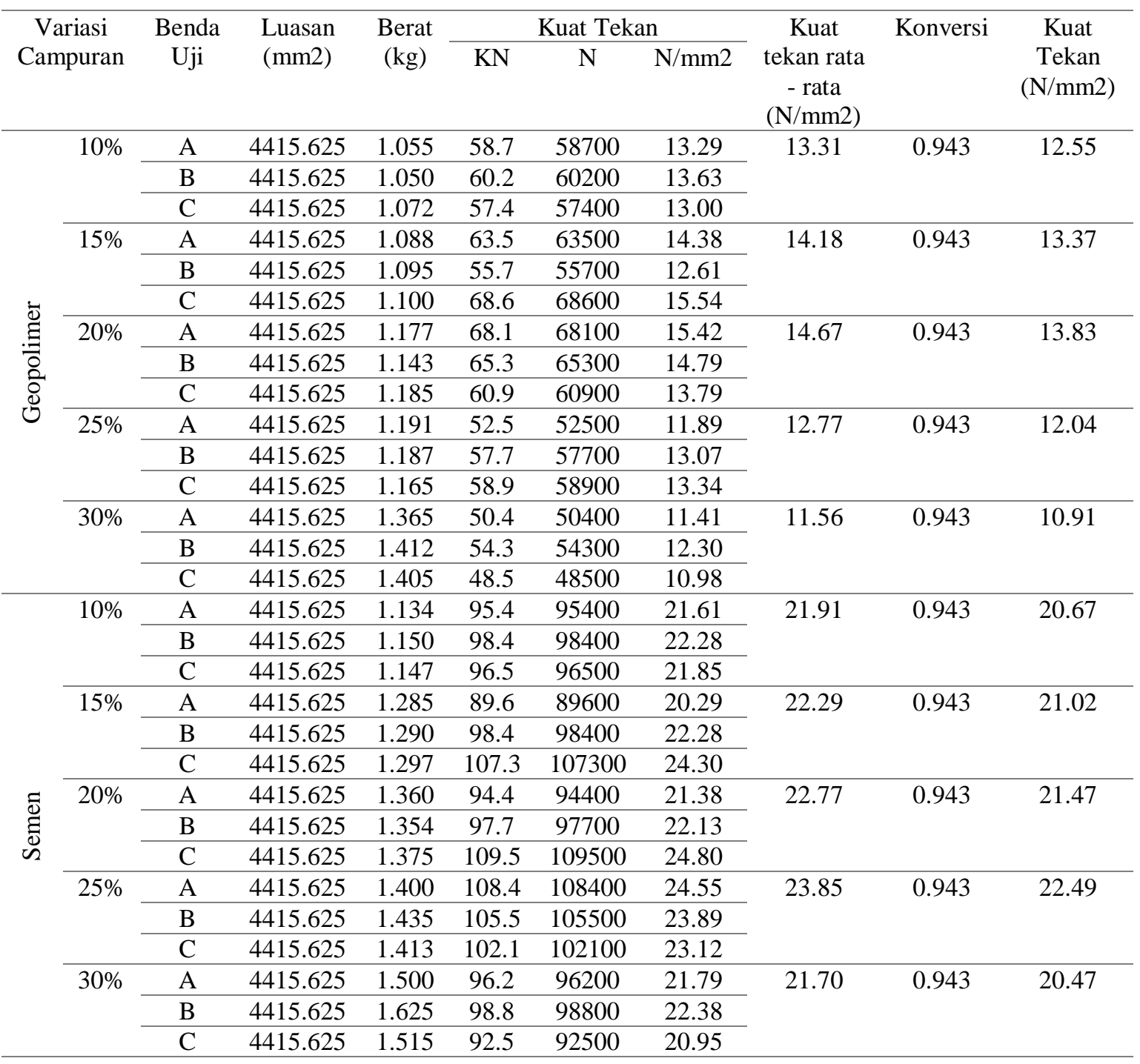

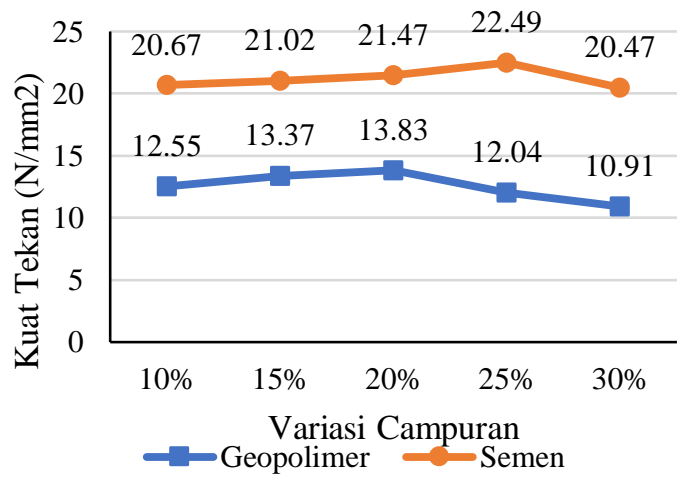

Gambar 1. Grafik Perbandingan Kuat Tekan

Dari pembacaan grafik kuat tekan, yaitu pada gambar 1, data prosentase pengganti material semen menggunakan material Geopolimer teroptimal pada prosentase 20\% dengan kuat tekan hancur $=13.83\left(\mathrm{~N} / \mathrm{mm}^{2}\right)$, sedangkan pada variasi penambahan $25 \%$ dan
$30 \%$ mengalami penurunan kuat tekan menjadi $12.04\left(\mathrm{~N} / \mathrm{mm}^{2}\right)$ dan $10.91\left(\mathrm{~N} / \mathrm{mm}^{2}\right)$. Akan tetapi, kenaikan justru terlihap pada variasi material semen teroptimal pada pesentase $25 \%$, dimana kuat tekan hancur $=$ $22.49\left(\mathrm{~N} / \mathrm{mm}^{2}\right)$. Kuat tekan beton dengan material geopolimer lebih kecil di bandingkan material semen diakibatkan terbentuknya sebruk warna putih pada pembuatan beton geopolimer akan menyebabkan turunnya kuat tekan beton. Hal ini disebabkan karena konsentrasi waterglass $\left(\mathrm{Na}_{2} \mathrm{SiO}_{3}\right)$ pada pembuatan beton yang tinggi menyebabkan Natrium yang berada dalam waterglass $\left(\mathrm{Na}_{2} \mathrm{SiO}_{3}\right)$ bereaksi dengan $\mathrm{CO}_{2}$ di udara menghasilkan Natrium karbonat (sebuk putih).

\section{Porousitas Beton}

Nilai porousitas beton disajikan dalam tabel 3 . 
Tabel 3. Hasil Pengujian Porousitas Beton

\begin{tabular}{|c|c|c|c|c|c|c|c|}
\hline \multicolumn{2}{|c|}{$\begin{array}{c}\text { Variasi } \\
\text { Campuran }\end{array}$} & $\begin{array}{c}\text { Benda } \\
\text { Uji }\end{array}$ & $\begin{array}{c}\text { Berat Kering } \\
\text { Oven (gr) }\end{array}$ & $\begin{array}{c}\text { Berat Beton } \\
\text { dalam Air (gr) }\end{array}$ & $\begin{array}{l}\text { Berat Beton } \\
\text { Kondisi SSD }\end{array}$ & $\begin{array}{c}\text { Porousitas } \\
(\%)\end{array}$ & $\begin{array}{c}\text { Porousitas } \\
\text { Rata-rata }\end{array}$ \\
\hline \multirow{15}{*}{ 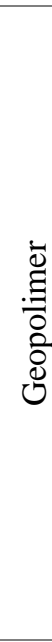 } & \multirow[t]{3}{*}{$10 \%$} & A & 1191 & 716 & 1251 & 11.215 & \multirow[t]{3}{*}{17.352} \\
\hline & & B & 1187 & 725 & 1302 & 19.931 & \\
\hline & & $\mathrm{C}$ & 1165 & 730 & 1280 & 20.909 & \\
\hline & \multirow[t]{3}{*}{$15 \%$} & A & 1088 & 667 & 1157 & 14.082 & \multirow[t]{3}{*}{18.736} \\
\hline & & B & 1095 & 660 & 1210 & 20.909 & \\
\hline & & C & 1100 & 673 & 1215 & 21.218 & \\
\hline & \multirow[t]{3}{*}{$20 \%$} & A & 1177 & 706 & 1247 & 12.939 & \multirow[t]{3}{*}{18.121} \\
\hline & & B & 1143 & 715 & 1258 & 21.179 & \\
\hline & & $\mathrm{C}$ & 1185 & 732 & 1300 & 20.246 & \\
\hline & \multirow[t]{3}{*}{$25 \%$} & A & 1191 & 716 & 1265 & 13.479 & \multirow[t]{3}{*}{16.796} \\
\hline & & B & 1187 & 725 & 1275 & 16.000 & \\
\hline & & C & 1165 & 730 & 1280 & 20.909 & \\
\hline & \multirow[t]{3}{*}{$30 \%$} & A & 1365 & 795 & 1413 & 7.767 & \multirow[t]{3}{*}{13.135} \\
\hline & & B & 1412 & 803 & 1527 & 15.884 & \\
\hline & & $\mathrm{C}$ & 1405 & 790 & 1520 & 15.753 & \\
\hline \multirow{15}{*}{ 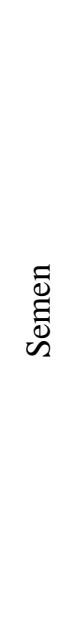 } & \multirow[t]{3}{*}{$10 \%$} & A & 1134 & 705 & 1186 & 10.811 & \multirow[t]{3}{*}{9.453} \\
\hline & & B & 1150 & 712 & 1199 & 10.062 & \\
\hline & & C & 1147 & 665 & 1186 & 7.486 & \\
\hline & \multirow[t]{3}{*}{$15 \%$} & A & 1500 & 892 & 1562 & 9.254 & \multirow[t]{3}{*}{8.818} \\
\hline & & B & 1625 & 968 & 1685 & 8.368 & \\
\hline & & C & 1515 & 875 & 1577 & 8.832 & \\
\hline & \multirow[t]{3}{*}{$20 \%$} & A & 1400 & 842 & 1452 & 8.525 & \multirow[t]{3}{*}{8.325} \\
\hline & & B & 1435 & 823 & 1480 & 6.849 & \\
\hline & & C & 1413 & 801 & 1478 & 9.601 & \\
\hline & \multirow[t]{3}{*}{$25 \%$} & A & 1360 & 805 & 1398 & 6.408 & \multirow[t]{3}{*}{7.640} \\
\hline & & B & 1354 & 845 & 1403 & 8.781 & \\
\hline & & $\mathrm{C}$ & 1375 & 814 & 1422 & 7.730 & \\
\hline & \multirow[t]{3}{*}{$30 \%$} & A & 1285 & 785 & 1350 & 11.504 & \multirow[t]{3}{*}{10.878} \\
\hline & & B & 1290 & 791 & 1370 & 13.817 & \\
\hline & & C & 1297 & 714 & 1343 & 7.313 & \\
\hline
\end{tabular}

Dari hasil perhitungan di dapatkan grafik seperti terlihat pada gambar 2 .

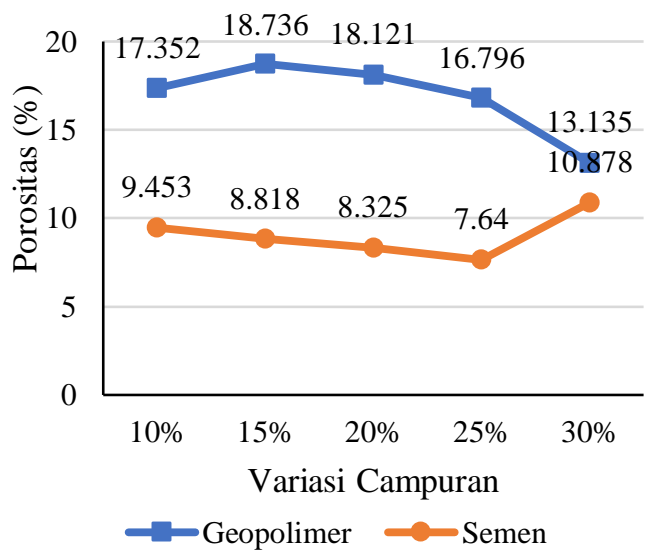

Gambar 2. Grafik Perbandingan Porousitas
Pada penelitian uji porousitas ini diketahui bahwa penggunaan bahan material geopolimer dengan variasi $10 \%, 15 \%, 20 \%$, $25 \%$ dan $30 \%$ memberikan kenaikan porousitas masing-masing sebesar $17.352 \%$, $18,736 \%, 18.121 \%$ kemudian turun hingga $13.135 \%$, pengujian tersebut cocok dengan judul yang menunjukan bahwa beton bersifat porous.

Sedangkan dari pembacaan grafik porousitas dengan material geopolimer, yaitu pada gambar 2, dapat dilihat kenaikan yang signifikan ditunjukkan pada material geopolimer variasi campuran $15 \%$, sedangkan yang menggunakan material semen dapat ditarik kesimpulan pembacaan hasil porousitas yang konstan. 
Dari hasil penelitian uji porousitas yang telah dilakukan bahwa adanya penggunaan semen dapat mengurangi nilai porousitas pada beton. Beton akan menjadi kedap air, karena penyerapan air tergantung pada pori-agregat pengisinya.

\section{Penentuan Kadar Optimum Geopolimer}

Berdasarkan grafik hubungan variasi campuran geopolimer dengan porositas dan kuat tekan beton, diperoleh variasi campuran geopolimer optimum pada $29 \%$, dengan kuat tekan beton $11 \mathrm{~N} / \mathrm{mm} 2$ dan porositas beton $14 \%$, seperti yang terlihat pada gambar 3 .

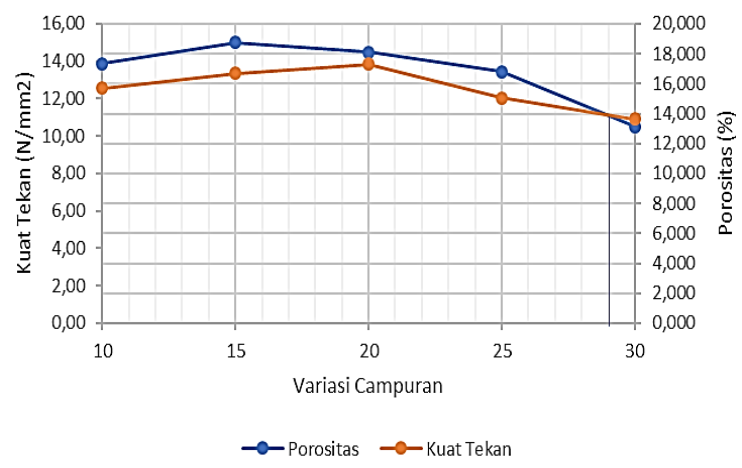

Gambar 3. Penentuan variasi campuran geopolimer

\section{KESIMPULAN DAN SARAN}

\section{Kesimpulan}

Hasil kuat tekan beton geopolimer tertinggi pada prosentase variasi $20 \%$ dengan kuat tekan hancur $=13.83$ $(\mathrm{N} / \mathrm{mm} 2)$, dan hasil porousitas tertinggi pada prosentase variasi $15 \%$ dengan nilai porousitas sebesar $18.736 \%$. Di dapat variasi campuran geopolimer optimum pada $29 \%$, dimana diperoleh nilai kuat tekan beton $11 \mathrm{~N} / \mathrm{mm} 2$ dan porousitas beton $14 \%$.

\section{Saran}

1. Perlu ditemukan metode atau cara yang cocok untuk mengurangi kehilangan air selama proses curing, agar terjadi proses polimerisasi yang sempurna.

2. Perlu ditemukan bahan tambah (Admixture) untuk mendapatkan kuat tekan, daya serap air, dan workability yang diinginkan pada pembuatan beton beton dengan material geopolimer.

\section{DAFTAR PUSTAKA}

Agusandra, A. (2013). Beton Polimer. http://senyum-itu.blogspot.co.id/ 2013/11/ beton-polimer.html. Diakses pada tanggal 11 Februari 2017.

Anonim. (2011). Repot On Pervious Concrete. American Concrete Institute, Farmington Hills, MI, USA.

ASTM Designation. C 39-94. 2005. Standard Test Method for Compressive Strength of Cylindrical Concrete Specimens.

Badan Standardisasi Nasional. (2002). Metode Pengujian Kekuatan Tekan Mortar Semen Portland Untuk Pekerjaan Sipil. SNI - 03-6825-2002.

Departemen Of Transportation. (2010). Geopoymer Concrete. Concrete Pavement Technologi program.

Davidovits, J. (2008). Geopolymer : Chemistry and Applications. Perancis: Geopolymer Institute.

Sanggapramana. (2011). Beton Geopolimer. https://sanggapramana.wordpress.com /2011/02/15/beton-geopolimer/. Diakses pada 20 Februari 2017.

Priyadarshana, T. Jayathunga, T., Dissanayake, R. Pervious Concrete - A Sustainable Choice In Civil Engineering And Construction. Sri Lanka.

Yusuf. L. (2006). Materi Kuliah Metode Konstruksi. "Construction Method Rigid Pavement". 